\title{
As encenações do capital no romantismo brasileiro
}

\section{Vivaldo Andrade dos Santos}

Resumo: O ensaio faz uma releitura do romantismo, a partir da nova crítica econômica que tem despontado no campo da literatura nas últimas décadas. Interessa, em particular, pontuar, na ficção, na poesia e no teatro de cunho romântico, a relação dessas obras com as finanças, o dinheiro e o capital. Destaca-se, neste ensaio, o romance Senhora e a peça $O$ crédito, ambos de José de Alencar, e os poemas "A minha desgraça" e "O editor", de Álvares de Azevedo. Palavras-chave: José de Alencar, Álvares de Azevedo, Senhora, O crédito, "A minha desgraça", “O editor", crítica econômica, dinheiro, finanças, capital, marxismo, romantismo, capitalismo.

Abstract: This essay reexamines the Brazilian Romanticism, considering the new economic criticism, which has emerged in the field of literary studies in the last decades. The author of the article is interested in shedding light to the theme of finances, money and capital in the romantic literary production. The essay focuses on the novel Senhora and the play O crédito, by José de Alencar, and in the poems "A minha desgraça" and "O editor", by Álvares de Azevedo. Keywords: José de Alencar, Álvares de Azevedo, Senhora, O crédito, "A minha desgraça", "O editor", economical criticism, money, finances, capital, Marxism, Romanticism, capitalism. 
No capítulo "Cultura e capital financeiro", de A cultura do dinheiro: ensaios sobre a globalização, Fredric Jameson chama a atenção para a importância do livro O longo século vinte, no sentido de que o autor, Giovanni Arrighi, salienta o problema das finanças como fundamentais para entender as facetas do capitalismo. Jameson pergunta:

Por que o monetarismo? Por que estamos prestando mais atenção aos investimentos e ao mercado de ações do que à produção industrial que, em todo caso, está prestes a desaparecer? Como se pode, para começar, obter lucros sem produção? De onde vem toda essa especulação excessiva?'

O horizonte das indagações de Jameson é uma reflexão sobre o modelo de produção marxista e também uma tentativa de compreender as mudanças históricas dos anos 1990, após a Guerra Fria. Seus comentários mostram a ansiedade do mundo contemporâneo, os sinais de uma sociedade pós-industrial, da qual o pós-modernismo e a globalização são sintomáticos. A ênfase do pensador sobre a hegemonia do capitalismo em nossa sociedade não somente revela a importância para se entender a esfera social de nossa vida presente, mas também nos convida à reflexão sobre as origens e o desenvolvimento do capitalismo. No campo dos estudos literários dos últimos anos, as ideias de Jameson e o retorno de Marx à cena acadêmica têm ganhado relevância. O último número da revista PMLA (Publications of the Modern Language Association of America), de janeiro de 2012, na seção teoria e metodologia, traz uma série de artigos dedicados ao tema "Economia, Finança, Capital, e Literatura". ${ }^{2}$ Este retorno da economia ao campo da literatura pode ser rastreado já no final dos anos 1990, quando Mark Osteen e Martha Woodmansee, professores de departamentos de Língua Inglesa, publicaram The new economic criticism: Studies at the intersection of literature and economics, livro cuja proposta indicava o novo surgimento da crítica econômica no campo intelectual dos anos 1990, uma continuação do que começou ao redor do final dos anos 1970 e início dos anos 1980. A assim chamada Nova crítica econômica [The new economic criticism] estava ligada a um campo de pesquisa da crítica interessado em estudar a relação entre literatura, cultura e economia. ${ }^{3}$

JAMESON, Fredric. A cultura do dinheiro: ensaios sobre a globalização. Trad. Maria Elisa Cevasco e Marcos César de Paula Sousa. Petrópolis: Vozes, 2001, p. 143. 
No campo do romantismo, a publicação recente de Real money and romanticism, de Matthew Rowlinson, é reflexo desta nova crítica econômica. Nesse livro, o crítico assinala que a historiografia literária não deu suficiente atenção ao fato de que a "literatura britânica do final do século XVIII e começo do século XIX foi definida pelas mudanças na estrutura econômica da indústria editorial e o status de commodity da propriedade intelectual". ${ }^{4}$ Rowlinson propõe uma nova leitura do romantismo britânico buscando entender as relações entre autores, a indústria gráfica e o capital no período romântico. A partir das ideias de Marx, Marcel Mauss e Jacques Lacan, o crítico examina as obras de Sir Walter Scott, Keats, estendendo sua análise até Charles Dickens, tradicionalmente fora do quadro romântico, mostrando como o sublime-romântico é atravessado pelas relações entre o capital e o trabalho, dinheiro, produção material e textual.

O objetivo deste ensaio é examinar alguns momentos no romantismo brasileiro em que o capital entra em cena. Interessa-me, neste estudo, refletir e pontuar alguns momentos em que o discurso do dinheiro entra em cena na literatura romântica brasileira.

\section{Cena I: a ficção}

O tema do dinheiro no romantismo não é novidade, embora não tenha recebido muita atenção por parte dos críticos nos últimos anos. A crítica histórico-materialista foi a primeira a chamar a atenção para o tema. No capítulo dedicado aos romances de José de Alencar, na sua Formação da literatura brasileira, Antonio Candido aponta três vertentes na obra do escritor cearense, os dois primeiros Alencares, sendo um "dos rapazes, heroico, altissonante" e outro "das mocinhas, gracioso, às vezes pelintra, outras, quase trágico". ${ }^{5}$ Mais adiante no ensaio, Candido salienta a

da desconstrução, semiótica, e das tendências formalistas tradicionais que imperaram nos anos 1970 e começo dos anos 1980; 2) a crise na indústria editorial acadêmica e a procura por novas abordagens teóricas; 3) o influxo dos estudos culturais, e sua ênfase em métodos de interdisciplinaridade, incluindo, neste caso, o trabalho dos economistas; 4) o lugar da economia na sociedade, tendo início nos anos 1980, acompanhado das discussões sobre bolsa de valores, juros, títulos, especulação, e assim por diante - os quais não se tinham observado em nossa sociedade desde a década de 1930. Cf. OSTEEN, Mark; WOODMANSEE, Martha. The new economic criticism: Studies at the intersection of literature and economics. Economics as social theory. London: Routledge, 1999, p. 3-4. 
existência de um terceiro Alencar. Um "Alencar que se poderia chamar dos adultos, dedicado aos 'temas profundos', formado por uma série de elementos pouco heroicos e pouco elegantes, mas denotadores dum senso artístico e humano que dá contorno aquilino a alguns dos seus perfis de homem e de mulher". ${ }^{6}$ Nesse "terceiro Alencar", o crítico debruça-se sobretudo nos romances Til, Senhora e Lucíola, A viuvinha, Diva, Pata da gazela, Tronco do ipê e Sonhos d'ouro. Para ele, o que merece atenção nesses romances alencarianos, "mais do que os ambientes, são as relações humanas que estuda em função deles". Essas relações, segundo o crítico, "estão ligadas ao nível econômico, que constitui preocupação central nos seus romances da cidade e da fazenda". Evidência maior disso é o clássico Senhora em que deparamos com a história da compra do amor de Seixas por Aurélia, a esposa outrora pobre e preterida que se faz rica. A conclusão de Candido indica que o senso apurado de observação de Alencar lhe permitiu distinguir "o conflito da condição econômica e social com a virtude, ou as leis da paixão", de forma que abrandou os efeitos do conflito, como é o caso do "happy end da forte história da conspurcação pelo dinheiro, que é Senhora". Essa ideia do dinheiro como vilão reaparecerá em outro ensaio de Candido sobre Senhora, no qual ele reafirma que, no romance de Alencar, "as relações humanas se deterioram por causa dos motivos econômicos", visto que "A heroína, endurecida do desejo de vingança, possibilitada pela posse do dinheiro, inteiriça a alma como se fosse agente duma operação de esmagamento do outro por meio do capital, que o reduz a coisa possuída". ${ }^{9}$

Estudando a obra de Alencar, Roberto Schwarz constata o descompasso entre a forma e o conteúdo da forma literária europeia no contexto brasileiro. O crítico assinala como o romance romântico em seu contexto original está ligado a uma lógica ideológica e estética próprias - romântica e do individualismo liberal - da sociedade europeia, que escapa ao autor de Senhora, dando à sua ficção um caráter de artificialidade. ${ }^{10}$ Mola mestra do romance, o dinheiro ganha atenção destacada pelo crítico. Na sua análise de Aurélia, heroína do romance Senhora, Schwarz observa:

ALENCAR. José de. Senhora. Edição crítica José Carlos Garbuglio. Rio de Janeiro: LTC, 1979, p. 262-4.

10 SCHWARZ, Roberto. "A importação do romance e suas contradições em Alencar". In: Ao vencedor as batatas: forma literária e processo social nos inicios do romance brasileiro. 5. ed. São Paulo: Duas Cidades/Editora 34, 2000 . 
[...] o dinheiro é rigorosamente a mediação maldita: questiona homens e coisas pela fatal suspeita, a que nada escapa, de que sejam mercáveis. Simetricamente, exaspera-se na moça o sentimento da pureza, expresso nos termos da moralidade mais convencional. Pureza e degradação, uma é talvez fingida, uma é intolerável: lançando-se de um a outro extremo, Aurélia dá origem a um movimento vertiginoso, de grande alcance ideológico - o alcance do dinheiro, esse "deus moderno" - e um pouco banal; falta complexidade a seus polos. A riqueza fica reduzida a um problema de virtude e corrupção, que é inflado, até tornar-se a medida de tudo."

Esta relação do dinheiro com a modernidade, enfatizada por Schwarz, é também sugerida por José Carlos Garbuglio, para quem a trama do romance de Alencar reproduz "a sociedade ociosa dos salões da Corte na segunda metade do século passado, com seu brilho de imitação europeia, a exibição de seu incipiente mundanismo, onde o dinheiro começa a mover seus cordéis e determinar o nível das relações, que desestrutura as velhas tradições". ${ }^{12}$ Tradições essas que dentro da ótica romântica desapareceram com o progresso e o desenvolvimento das cidades, que, impulsionados pelo motor do capital, debilitaram a alma e a pessoa.

\section{Cena II: o teatro}

O tema do dinheiro em Alencar aparece também na peça O crédito (1857).13 O crédito é uma comédia que analisa a vida social de um setor da burguesia carioca em meados do século xıx. O tema da peça gira em torno das artimanhas de vários indivíduos para se apoderarem de parte da fortuna de um rico comerciante, que dotara os filhos com duzentos contos cada um. Os personagens principais incluem: Pacheco (capitalista, pai de Julieta, casado com D. Antonia), Oliveira (negociante a quem Julieta é prometida), Borges (empregado público, pai de Cecília, que nutre uma paixão por Hipólito - jovem médico e rico), Guimarães (jovem desempregado), Rodrigo (protagonista, jovem engenheiro, apaixonado por Julieta, mas por quem Olímpia, esposa de Borges, nutre um amor), e finalmente Macedo (o agiota).

ALENCAR, José de. O crédito, 1857, <http://www.biblio.com.br/defaultz.asp?link=http://www.biblio.com. $\mathrm{br} /$ conteudo/JosedeAlencar/ocredito.htm> 
Interessa-me salientar na peça a visão do personagem Macedo, o agiota, e Rodrigo, o jovem engenheiro, com respeito ao capital. Macedo é o agiota irresponsável, explorador ganancioso, cuja existência se resume à pura especulação. Quando expulso da casa de Pacheco, depois de reveladas as suas falcatruas econômicas com o dinheiro dele, justifica o seu comportamento:

Como quiser!... Nunca estudei moral, Sr. Pacheco, e por isso não entendo essas distinções filosóficas. Sou um homem prático, um homem de negócios; trato da minha vida sem me ocupar com as dos outros. Podem dizer que sou agiota, especulador, que vivo de jogar na Praça. Pouco me importa! Estou convencido que só há na sociedade dois poderes reais: a lei e o dinheiro. Respeito uma, e ganho o outro. Tudo que dá a riqueza é bom; tudo que a lei pune, para mim é justo e honesto. Eis o meu princípio. (Ato v, cena XviII)

Para Macedo, o poder do dinheiro tem sua lei própria e escapa a qualquer ideia moral. Macedo está, como se vê, sublinhando uma visão comum que o capitalismo desperta; isto é: se o capitalismo traz algum benefício à humanidade, se o mesmo é do Bem ou do Mal, ou é destituído de qualquer moralidade, como sugere Robert C. Solomon. ${ }^{14} \mathrm{E}$, nesse sentido, também a frase "Nunca estudei moral", do antagonista na peça alencariana, põe em questão um problema, o tema dos sentimentos morais, discutido por Adam Smith, para quem, por mais egoísta que seja, nenhum ser humano é desprovido de um sentimento de compaixão pelo outro: $:^{15}$

How selfish soever man may be supposed, there are evidently some principles in his nature, which interest him in the fortune of others, and render their happiness necessary to him, though he derives nothing from it except the pleasure of seeing it [...]. The greatest ruffian, the most hardened violator of the laws of society, is not altogether without it.

Como podemos ver, para Macedo a existência se resume ao pragmatismo completamente alheio a qualquer ideal ético. Alencar pinta nesse retrato do personagem

14 "Free enterprise, sympathy, and virtue", p. 17. O artigo de Solomon é parte de um livro organizado por um grupo de pesquisadores de diversas disciplinas (direito, economia, biologia, filosofia, neurociência, zoologia, ciências políticas, negócios), que procura pensar a noção de valor na economia. Ver: Moral markets: the critical role of values in the economy. Paul J. Zak (Ed.). Princeton: Princeton University Press, 2008. SMITH, Adam. The theory of moral sentiments, 1759, <http://www.econlib.org/library/Smith/smMS.html>.

Teresa revista de Literatura Brasileira [12|13]; São Paulo, p. 192-204, 2013 • 197 
o emblemático homo economicus - indivíduo acima de qualquer moral, ética ou de piedade, calculista e frio, cujo sentido existencial se resume ao lucro.

No entanto, se a lei dos homens não é capaz de punir esse tipo social representado por Macedo, é o próprio dinheiro ou a relação das pessoas com o dinheiro que cumpre essa função pelo desprezo humano ao materialismo puro, como se observa no comportamento de personagens como D. Olímpia e Guimarães, iluminados pela inteligência, ou o senso moral de Rodrigo, protagonista, para quem

A missão do crédito é outra: é nivelar os homens pelo trabalho e dar à atividade os meios de criar e produzir. Outrora, para adquirir-se uma fortuna, era preciso consumir toda a existência em privações, juntar-se real por real. [...] Um dia, porém, um homem de dinheiro compreendeu que o trabalho e a probidade eram a melhor garantia do que a fortuna que o acaso pode destruir em um momento. Esse homem chamou os amigos pobres, mas honestos e empreendedores, e confiou-lhes os seus capitais para que eles realizassem as suas ideias. O crédito estava criado. [...] uma palavra o define: é a regeneração do dinheiro. O orgulho dos ricos tinha inventado a soberania da riqueza, soberania bastarda e ridícula, o crédito destronizou esta soberania: do ouro que era senhor, fez um escravo, e mandou-lhe que servisse à inteligência, a verdadeira rainha do mundo! (Ato I, cena IX)

Se para o personagem de Macedo a visão econômica é definida pura e simplesmente pela acumulação e especulação do capital, ao contrário, para Rodrigo ela se define pelo sentido pragmático e de circulação do capital. Do seu ponto de vista, o crédito e, por extensão, o capital têm a função de "nivelar os homens pelo trabalho", por meio do desenvovimento (criação) e produção. Uma vez posto em circulação, o dinheiro, outrora nas mãos de uns poucos, passa, agora mediado, vale ressaltar, pelo crédito, regenera-se. A "regeneração do dinheiro" significa, nessa perspectiva, o destronamento da soberania dos ricos. Dentro dessa visão, é fundamental o conceito de circulação. A passagem do senhorio do ouro à condição de escravo, dentro dessa nova lógica capitalista, é o fim do ouro como comodidade, como meio apenas de troca, conforme explica Marx, ou seja, como instrumento de circulação. ${ }^{16}$ Marx salienta: "The accumulation of gold and silver, of money, is the first historic appearance of the gathering-together of capital and the first great means thereto; but, as such, it is not yet accumulation of capital. For that, the re-entry of what has been accumulated into circuNicolaus. New York: Penguin Books, 1973, p. 186. 
lation would itself have to be posited as the moment and the means of accumulation". ${ }^{17}$ Para Marx, "Circulation is an inescapable condition for capital, a condition posited by its own nature, since circulation is the passing of capital through the various conceptually determined moments of its necessary metamorphosis - its life process". ${ }^{18}$ Assim, uma vez em circulação, o capital está em constante transformação, metamorfoseando-se. Esta visão é também compartilhada por Fernand Braudel, que afirma ser o dinheiro o agente da economia de mercado. Ele, o dinheiro, acelera o intercâmbio e cria a rede de comércio entre os habitantes da cidade. Braudel, enfim, afirma que "as cidades somente existem por causa do dinheiro, e ambos são responsáveis pela fabricação da modernidade". ${ }^{19}$ Além da noção de circulação, na fala de Rodrigo observa-se ainda outro aspecto de crucial importância na lógica do crescimento econômico: "Esse homem chamou os amigos pobres, mas honestos e empreendedores, e confiou-lhes os seus capitais para que eles realizassem as suas ideias". Aqui se faz notar a questão da fé, confiabilidade e dependência, como analisam Paul J. Zak e Stephen Knack nos seus estudos sobre o papel da confiança na economia e nas interações sociais. ${ }^{20}$ Flávio Aguiar destaca, no seu estudo sobre a obra, a relação do tema com o surgimento desse instrumento nas transações mercantis da época em que foi escrita. O crítico indica também o diálogo de Alencar com La question d'argent, de Dumas Filho. Na sua leitura, de cunho diretamente mais sociológico, de O crédito, Aguiar desmascara de forma incisiva o lugar social do personagem Rodrigo e de onde se origina seu discurso sobre o capital. Para ele, Alencar "nacionalizou" o tema do dinheiro, tema presente

17 Idem, p. 233.

18 Idem, p. 658. Marx também salienta que "The circulation of money, regarded for itself, necessarily becomes extinguished in money as a static thing. The circulation of capital constantly ignites itself anew, divides into its different moments, and is a perpetuum mobile. (Idem, p. 516.)

19 Segundo Braudel, "The truth is that money and cities have always been a part of daily routine, yet they are present in the modern world as well. Money is a very old invention, if one subsumes under that name every means by which exchange is accelerated. And without exchange, there is no society. Cities, too, have existed since prehistoric times. They are multicenturied structures of the most ordinary way of life. But they are also multipliers, capable of adapting to change and helping to bring it about. One might say that cities and money created modernity; but conversely, according to George Gurvitch's law of reciprocity, modernity - the changing mass of men's lives - promoted the expansion of money and led to the growing tyranny of the cities. Cities and money are at one and the same time motors and indicators; they provoke and indicate change". BRAUDEL, Fernand. Afterthoughts on material civilization and capitalism. Translated by Patricia M. Ranum. Baltimore: The Johns Hopkins Press, 1977, p. 15.

20 ZAK, Paul J.; KNACK, Stephen. "Trust and growth". Royal Economic Society Economic Journal. 111:470 (2001): 295-321. 
na obra de Dumas Filho. ${ }^{21}$ Sobre a visão do capital de Rodrigo, Aguiar ressalta que "o trabalho é visto do ponto de vista burguês, de quem o "financia", e do ponto de vista do engenheiro, de quem administra esse "financiamento"; é deste pacto que Rodrigo é o arauto. "O trabalho propriamente produtivo - que transforma a natureza e faz da matéria-prima mercadoria - está ausente dessa retórica, oculto, num passe de mágica ideológico, sob o trabalho do administrador, cuja função é a de organizar o trabalho alheio em proveito de terceiros."22 Em conclusão, vale dizer que Rodrigo propõe uma espécie de capitalismo humanizado, em que o capital, uma vez posto em circulação, fundamentado no trabalho e administrado pela razão, realiza a ascese individual.

\section{Cena III: a poesia}

O tema do dinheiro também é comum à poesia romântica. ${ }^{23} \mathrm{~A}$ estrofe final do poema "Minha desgraça" de Álvares de Azevedo é ilustrativo:

Minha desgraça, ó cândida donzela, O que faz que o meu peito assim blasfema, É ter para escrever todo um poema, E não ter um vintém para uma vela.

Uma questão importante emerge nos versos acima: a relação entre poesia, dinheiro e o idealismo romântico. Martha Woodmansee, ${ }^{24}$ estudando o romantismo alemão, mostra a relação entre o trabalho, entendido como atividade humana capaz de transformar a natureza a partir de determinada matéria-prima, e o trabalho poético, entendido como criação a partir do talento individual. A crítica mostra como no romantismo o discurso da inspiração ou do gênio do poeta deu origem à ideia de que a criação individual era distinta e originalmente o "product-and property-of the wri-

AGUIAR, Flávio. A comédia nacional no teatro de José de Alencar. São Paulo: Ática, 1984, p. 60. (Coleção Ensaios)

22 Idem, p. 52-3.

23 No romantismo brasileiro talvez a referência maior seja O guesa errante, de Joaquim de Sousândrade, especialmente o episódio "O inferno de Wall Street", de que optei por não tratar neste artigo.

24 "The Genius and the Copyright: Economic and Legal Conditions of the Emergence of the 'Author"'. In: Eighteenth Century Studies, Vol. 17, n. 4, Special Issue: The Printed Word in the Eighteenth Century (Summer, 1984), p. 425-448. 
ter". Para ela, a categoria "autor" é uma invenção moderna. No caso alemão, o conceito de "autor" está associado ao surgimento no século XVIII de um grupo de escritores que vislumbrou no fazer literário a possibilidade de se ganhar a vida diante de um público leitor que começava a nascer. Segundo Woodmansee, esta nova definição da natureza da escrita se distanciava da ideia de escritor no renascimento e no período neoclássico, para quem o escritor era uma espécie de artesão, um "master of a body of rules, preserved and handed down to him in rhetoric and poetics, for manipulating traditional materials in order to achieve the effects prescribed by the cultivated audience of the court to which he owed both his livelihood and social status". ${ }^{25}$ Ex exatamente nos raros momentos em que o talento individual superou a criação encomendada que a explicação para sua origem passou a ser dada pela inspiração externa a ele, Deus ou musa inspiradora. Vale aclarar que minha leitura mais de caráter materialista da presença da economia no romantismo destoa do enfoque idealista que para muitos caracterizou o período. Penso, por exemplo, no argumento de Benedito Nunes, ${ }^{26}$ para quem no romantismo há

[...] o nivelamento dos valores morais à regra benthamiana do maior interesse e da melhor utilidade, a marginalização social de toda atividade improdutiva, o princípio fiduciário da moralidade burguesa, as relações possessivas da moral doméstica e do casamento, o filisteísmo como atitude da maioria dominante em relação às letras e às artes. ${ }^{27}$

Vagner Camilo aponta, no seu estudo sobre o riso e o humor na poesia romântica, Risos entre pares (1997), um momento em que a poesia de Álvares de Azevedo se aproxima do humour, sobretudo no que diz respeito à "inserção social do poeta". ${ }^{28}$ $\mathrm{Na}$ sua análise do poema "O editor", Camilo assinala que, embora o poeta trate de um tema problemático como a relação entre a poesia e a economia, disso "não chega a resultar uma visão mais aprofundada e problematizante". ${ }^{29}$ Isso porque, segundo o crítico, a poetização do tema é, antes de tudo, uma "pose do poeta maldito" que o

\section{Emergence of the 'Author"'. In: Eighteenth-Century Studies, op. cit., p. 426.}

26 NUNES, Benedito. "A visão romântica". In: GUINSBURG, J. (Org.) O romantismo. São Paulo: Perspectiva, 1978.

27 Idem, p. 55.

28 CAMILO, Vagner. Risos entre pares. São Paulo: Edusp/FAPESP, 1998, p. 69. Camilo indica a recorrência temática presente em "O editor" e, ainda, em poemas tais como "O dinheiro", "Um cadáver de poeta" e "Minha desgraça".

29 Idem, p. 69. 
jovem poeta constrói para si. ${ }^{30}$ Pose esta que vem de uma tradição literária, como os versos finais de "Minha desgraça", que fazem ecoar os versos de "O editor" em "Que Tasso lastimou-se da penúria/ De não ter um ceitil para candeia" -, em que o poeta posa de Tasso em sua miséria. Vale, contudo, retomar o tema apontado por Camilo, embora em Azevedo faça parte das máscaras do poeta.

Os versos finais do poema "Minha desgraça" ("É ter para escrever todo um poema,/ E não ter um vintém para uma vela."), ainda que marcados pelo humor, pelo riso da "desgraça" alheia, deixam-nos entrever a ansiedade material do poeta. Do seu ponto de vista, a produção do poético não encontra o reconhecimento econômico que o poeta espera, pois a poesia não possui o caráter de mercadoria, e de troca, esperado dentro da lógica do capital. Para entrar nessa lógica é preciso que a poesia passe a ser uma commodity, e que exista para isso um público leitor, enfim, um público consumidor.

É, porém, no poema “O editor" que Azevedo mostra como o dinheiro é um dos grandes temas da poesia:

Demais - infelizmente é bem verdade

Que Tasso lastimou-se da penúria

De não ter um ceitil para candeia.

Provo com isso que do mundo todo

O sol é este Deus indefinível,

Ouro, prata, papel, ou mesmo cobre,

Mais santo do que os Papas - o dinheiro!

Byron no seu Don Juan votou-lhe cantos,

Filinto Elísio e Tolentino o sonham,

[...].

O poeta estabelece uma genealogia literária em que o dinheiro não é somente tema da literatura, mas objeto de idolatria pelos escritores. O "Deus indefinível" ganha diversas roupagens ("Ouro, prata, papel, ou mesmo cobre"), e é a "Palavra mágica da vida,/ que vibra musical em todo mundo”. Nesse universo poético e econômico, a poesia se reduz ao tilintar de moedas. Do ponto de vista do poeta, o dinheiro é a grande tentação, diga-se de passagem, do diabo ("Se creio que Satã, à noite, veio/ Aos ouvidos de Adão adormecido/ Na sua hora primeira, murmurar-lhe/ Essa palavra

30 Idem, p. 70. 
mágica da vida"), capaz mesmo de reescrever a cena do pecado original de Adão e Eva no Paraíso se possível fosse:

Se houvesse o Deus-Vintém no Paraíso

Eva não se tentava pelas frutas,

Pela rubra maçã não se perdera:

Preferira decerto o louro amante

Que tine tão suave e é tão macio!

No romantismo, afirma Benedito Nunes, "Firmava-se, enfim, alçada a um plano ideal, a superioridade da arte ou da poesia, como um domínio privilegiado e transcendente, veículo de todos os valores e princípios da formação espiritual do homem". ${ }^{31}$ Contudo, conforme vemos no poema "O editor", a pose do poeta maldito, como sugere Camilo, desmascara a própria relação entre poeta e economia, colocando em evidência o seu lado materialista, distanciado do idealismo com o qual se procura caracterizar os românticos:

Se não faltasse o tempo a meus trabalhos,

Eu mostraria quanto o povo mente

Quando diz que - a poesia enjeita e odeia

As moedinhas doiradas. É mentira!

Desde Homero (que até pedia cobre),

Virgílio, Horácio, Calderón, Racine,

Boileau e o fabuleiro La Fontaine

E tantos que melhor decerto fora

De poetas copiar algum catálogo,

Todos a mil e mil por ele vivem

E alguns chegaram a morrer por ele!

Eu só peço licença de fazer-vos

Uma simples pergunta: - na gaveta

Se Camões visse o brilho do dinheiro...

Malfilâtre, Gilbert, o altivo Chatterton

Se o tivessem nas rotas algibeiras,

Acaso blasfemando morreriam?

31 NUNES, Benedito. Op. cit., p. 71. 


\section{Cena final}

A primeira grande crise econômica do século xxI, que aconteceu no ano de 2008, trouxe de volta à cena a importância da economia na nossa vida cotidiana. A crise tem sido extraordinária, considerando-se o momento da história em que ela aconteceu e a dimensão dos seus efeitos, numa sociedade pós-industrial e num mundo contemporâneo globalizado. Na dinâmica do capitalismo o caráter extraordinário da crise é natural. A história do capitalismo mostra-nos como as crises econômicas forçam uma mudança e um reajuste nas práticas financeiras em vista do capital. ${ }^{32}$ Do mesmo modo, a relação entre literatura e economia também não é novidade, como, talvez, um congresso interdisciplinar organizado em torno do tema do dinheiro possa sugerir, ou como procurei demonstrar neste ensaio. ${ }^{33}$ Vejam-se as publicações sobre o tema, em especial de Marc Shell, autor de The economy of literature (Johns Hopkins, 1978), Richard T. Gray, autor de Money matters: economics and the German cultural imagination, 1770-1850 (University of Washington Press, 2008). No que diz respeito especificamente ao romantismo, vale citar aqui a publicação mais recente de Matthew Rowlinson, autor de Real money and romanticism (Cambridge University Press, 2010). No Brasil, algumas obras também apontam no caminho dessa nova crítica. Entre elas, cito os dois livros organizados por Gustavo H. B. Franco, $A$ economia em pessoa: verbetes contemporâneos e ensaios empresariais do poeta (Zahar, 2007), sobre a relação do poeta maior português com a economia, e A economia em Machado de Assis: O olhar oblíquo do acionista (Zahar, 2008); A aventura do dinheiro - uma crônica da história milenar da moeda (Publifolha, 2009, edição de bolso), do jornalista Oscar Pilagallo, e mesmo o mais recente, Dinheiro e magia: uma crítica da economia moderna à luz do Fausto de Goethe, de Hans Christoph Binswanger, cujo prefácio é de Gustavo H. B. Franco (Zahar, 2010).

Vivaldo Andrade dos Santos é professor-associado de Português e Literatura Brasileira, Georgetown University, Washington, DC.

Ver a discussão sobre o tema no livro de Charles Poor Kindleberger, Manias, panics and crashes: A history of financial crises. Hoboken, N. J.: John Wiley \& Sons, 2005

Congresso The Cultural Life of Money, organizado pela Universidade Católica Portuguesa-Lisboa, 12-13 de novembro de 2009 